\title{
Gold Price Forecasting Using LSTM, Bi-LSTM and GRU
}

\author{
Mustafa Yurtsever ${ }^{1 *}$ \\ 1* Dokuz Eylül Üniversitesi, Departmant of Information Technology, İzmir, Turkey, (ORCID: 0000-0003-2232-0542), mustafa.yurtsever@deu.edu.tr
}

(First received 29 June 2021 and in final form 6 December 2021)

(DOI: 10.31590/ejosat.959405)

ATIF/REFERENCE: Yurtsever, M. (2021). Gold Price Forecasting Using LSTM, Bi-LSTM and GRU. European Journal of Science and Technology, (31), 341-347.

\begin{abstract}
Due to the multifactorial and non-linear nature of the gold market, it is difficult to predict the gold price. The gold price is affected by many external factors, such as market environment, economic crises, oil price increases, tax advantages and interest rates. Therefore, multivariate models can better predict the gold price than univariate models. This study investigated the effects of gold price, crude oil price, consumer price index, exchange rate index, stock market index, and interest indicators between 2001 and 2021 . Models created using LSTM, Bi-LSTM and GRU methods were evaluated using lowest Root Mean Square Error (RMSE), Mean Absolute Percent Error (MAPE) and Mean Absolute Error (MAE) metrics. The LSTM model performed best, with 3.48 MAPE, 61,728 RMSE and 48.85 MAE values.
\end{abstract}

Keywords: Gold Price, LSTM, Bi-LSTM, GRU.

\section{LSTM, Bi-LSTM ve GRU ile Altın Fiyatı Tahmini}

$\ddot{O ̈ z}$

Altın piyasasının çok faktörlü ve doğrusal olmayan özelliği nedeniyle altın fiyatının tahminini yapmak zordur. Altın fiyatı, piyasa ortamı, ekonomik kriz, petrol fiyatlarındaki artış, vergi avantajları, faiz oranları gibi dış faktörlerden etkilenmektedir. Bu nedenle çok değişkenli modeller altın fiyatını tahmin etmede daha iyi sonuçlar verebilmektedir. Makalede, 2001-2021 y1lları arasında altın fiyatı, ham petrol fiyatı, üretici fiyat endeksi, döviz kuru endeksi, borsa endeksi ve faiz göstergeleri kullanılmıştır. LSTM, Bi-LSTM ve GRU yöntemleri kullanılarak oluşturulan modeller en düşük Kök Ortalama Kare Hata (RMSE), Ortalama Mutlak Yüzde Hata (MAPE) ve Ortalama Mutlak Hata (MAE) metrikleri ile değerlendirilmiştir. LSTM modeli 3,48 MAPE, 61,728 RMSE ve 48,85 MAE değerleri ile en iyi yöntem olmuştur.

Anahtar Kelimeler: Altın Fiyatı, LSTM, Bi-LSTM, GRU

\footnotetext{
* Corresponding Author: mustafa.yurtsever@deu.edu.tr
} 


\section{Introduction}

A time series is a sequential collection of data related to any event based on time. Time series analysis is an important technique for producing insights by analyzing historical events and transactions over time (Parmezan et al., 2019). Relationships derived from past events observed in succession are useful for predicting the future.

A multivariate time series is one in which the output is predicted by more than one time-dependent variable (Nguyen et al., 2021). That is, the estimation depends not only on historical data but also on relationships between variables, which are usually correlated. Better prediction results can be obtained by including all relevant variables in the model instead of modeling a single variable (Du et al., 2020). However, it is important to select an appropriate set of variables as input is important for accurate prediction (Munkhdalai et al., 2019).

Different time series analysis methods are used in the literature. The most commonly used methods for univariate analyses include linear regression, exponential smoothing and autoaggressive integrated moving average methods, such as ARIMA. ARIMA models, developed by Box and Jenkins, are the most commonly used method. However, these models are not sufficient for nonlinear time series (Zhang, 2003; Shen et al., 2020). Instead, machine learning and neural networks are used in a wide variety of applications due to their superior ability to understand nonlinear relationships between complex inputs and outputs. The prominence of deep learning (LeCun et al., 2015; Schmidhuber, 2015), with its strong representation, has brought different applications in many fields.

The Recurrent Neural Network model (RNN) is designed to model temporal dependencies in time series. However, there is a gradient problem (Karim et al., 2019). Hochreiter and Schmidhuber (1997) therefore developed the Long Short-Term Memory (LSTM) model, which they presented as a new method. This adds a gate mechanism into the RNN layers to control information flow. By retaining knowledge of many previous timesteps, this method derives relationships from the information in older timesteps more effectively than traditional RNN. LSTM is also designed to store information better, thereby eliminating the short-term memory problem of standard RNN. (Gunduz, 2021). LSTM is used in many fields, but particularly finance (Alpay, 2020; Güleryüz and Özden, 2020; Aygun and Kabakcu Gunay, 2021; Y1ldırım et al., 2021). The Gated Recurrent Units (GRU) method is also frequently used in time series problems as it has a similar structure to LSTM (Shen et al., 2018; Dutta et al., 2020).

Gold is used in various industries, including electronics, aerospace, medicine and jewelry. It is also used as an investment tool. Gold is considered a precious metal for both its commodity and monetary qualities. It is simultaneously a commodity, a precious metal and a currency. Within the financial market, the gold market attracts great attention from individuals, institutional investors and governments.

As a precious metal, gold has always been considered valuable. It has also demonstrated an extraordinary ability to maintain its value, even during economic, financial and political crises. Central banks worldwide maintain gold reserves to guarantee the money of depositors, external debt creditors and foreign exchange holders. Central banks also use gold reserves to e-ISSN: 2148-2683 control inflation. Although gold is no longer used as money, it is one of the most important commodities traded worldwide. For example, it is the best hedging tool, especially for governments and central banks. According to Dar and Maitra (2017), gold retains its value in times of economic crisis when the value of other assets drops significantly. Because of its popularity and importance, forecasting gold prices is very important, not only for economists, but also for government treasury units, central banks, financial institutions and individuals.

Due to the global nature of the gold market, it is a fluctuating nonlinear system influenced by many factors (Alameer et al., 2019). Consequently, the causes of gold price fluctuations are very complex (Livieris et al., 2020). Therefore, it is a challenge to create models that can predict the future gold price.

Researchers have developed various models to predict the gold price. Parisi et al. (2008) used iterative and rolling neural network models while Yazdani-Chamzini et al. (2012) used the Adaptive Neuro-fuzzy Inference System and Artificial Neural Network (ANN) model, which they compared to the ARIMA model. Li (2014) applied the wavelet neural network method together with a new artificial bee colony algorithm.

Xian et al. (2016) created a gold price model using ensemble empirical model decomposition and independent component analysis while Gangopadhyay et al. (2016) used the vector error correction model. Sivalingam et al. (2016) developed extreme learning machines, which used the past prices of gold, silver and oil, the S\&P 500 index and the exchange rate. Jianwei et al. (2019) presented a new combination based on independent component analysis and gated recurrent unit neural network methods. Alameer et al. (2019) used an advanced multilayer perceptron neural network and whale optimization algorithm. Risse (2019) combined discrete wavelet decomposition and support vector regression methods. Hassani et al. (2015) used multivariate Bayesian autoregression (BAR) models and five variations of Bayesian VAR. Zhang and Ci (2020) used the deep belief network method while Weng et al. (2020) aimed to reduce the effect of randomness on prediction results by using a genetic algorithm and improved extreme machine learning.

Many empirical studies identified factors affecting the gold price in order to estimate it. Statistical and econometric analyses suggest various explanatory variables. The link between gold and oil prices is typically positive in that crises tend to raise both (Shafiee and Topal, 2010; Yazdani-Chamzini et al., 2012; Chen and $\mathrm{Xu}, 2019)$. Similarly, Wang and Chueh (2013) concluded that gold and oil prices increase each other whereas interest rates and the US dollar reduces the gold price. Currency depreciations also make investors to turn to gold, which explains the negative relationship between the gold price and the exchange rate (Giannellis and Koukouritakis, 2019). Investors include gold in their portfolios to protect against inflation (Gokmenoglu and Fazlollahi, 2015).

The gold price is related to the stock market index, exchange rate, consumer price index (CPI), US bond rates and oil price (Gangopadhyay et al., 2016). CPI is one of the important indicators of inflation. In the long run, the US CPI and the gold price are positively correlated. Since gold resists inflation, investors prefer it whenever there is high inflation. Thus, when CPI increases, the gold price also increases (Liu and Li, 2017). The consumer price index and the dollar also affect gold prices (Xian et al., 2016), with a negative relationship between the gold price and the interest rate as increasing interest rates reduce 
interest in gold (Giannellis and Koukouritakis, 2019). Mensi et al. (2013) examined correlations and volatility transfer between various commodities, including gold, oil and the stock market. They found that the S\&P500 price affects the volatility of gold and oil prices. The gold price rises at the rate of general inflation over time, which makes it is an effective hedge against inflation (Ghosh et al., 2004). In the very long run, gold is useful as a partial protection as a cointegrating relationship prevails (Beckmann \& Czudaj, 2013). However, the evidence for effective protection against unexpected inflation is weak (Erb and Harvey, 2013).

This article provides some new information for forecasting the gold price based on economic indicators. The LSTM, BiLSTM and GRU methods were used to predict the gold price. The data set was created from various economic indicators and the gold ounce price between 2001 and 2021. Although the gold price has been estimated with different methods in the literature, it is original in terms of the variables used in the study.

The next section explains the methodology used in the study while the third section presents the data set and application procedures. The fourth chapter presents the findings while the last section discusses the findings in relation to the literature, suggests some theoretical and practical contributions, and offers some conclusions.

\section{Material and Method}

\subsection{LSTM, Bi-LSTM}

The LSTM deep learning algorithm is a recurrent neural network introduced by Hochreiter and Schmidhuber in 1997 to eliminate the disadvantages of RNN architecture. In the RNN approach, each item in the input data is iteratively examined by considering the value of the previous output. In general, RNN is disadvantaged because gradients are lost when learning long data sequences. LSTM solves this problem by determining when certain information is used or not. An LSTM model consists of the input layer, hidden layers and output layer. Each block has several memory cells attached to it and three multiplier units, input, output, and forget gates. Depending on these components, the LSTM cell block contains three gates and a memory cell unit capable of forgetting or memorizing information to determine how much information should be transferred to the next cell. Figure 1 shows the LSTM architecture.

Figure 1. LSTM Architecture (Olah, 2015).

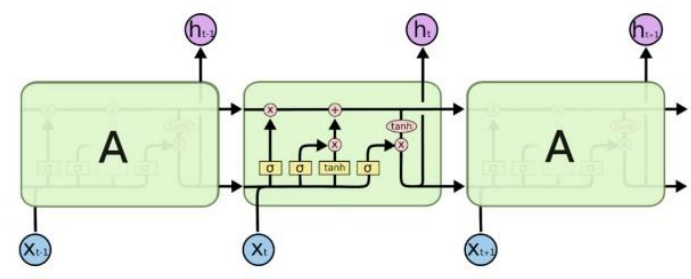

The equations that perform these operations are as follows.

$$
\begin{aligned}
& f_{t}=\sigma\left(W_{f} *\left[h_{t-1}, x_{t}\right]+b_{f}\right) \\
& i_{t}=\sigma\left(W_{i} *\left[h_{t-1}, x_{t}\right]+b_{i}\right)
\end{aligned}
$$

$$
\begin{aligned}
& \dot{C}_{t}=\tanh \left(W_{C} *\left[h_{t-1}, x_{t}\right]+b_{C}\right) \\
& C_{t}=f_{t} * C_{t-1}+i_{t} * \dot{C}_{t} \\
& o_{t}=\sigma\left(W_{o} *\left[h_{t-1}, x_{t}\right]+b_{o}\right) \\
& h_{t}=o_{t} * \tanh \left(C_{t}\right)
\end{aligned}
$$

To overcome the limitations of the LSTM cell, which can work on the previous content but cannot use the future, Schuster and Paliwal (1997) presented bidirectional recurrent neural networks consisting of two different LSTM hidden layers with similar outputs in opposite directions. With this architecture, previous and future information is used in the output layer. BiLSTM, in particular, integrates the concept of time order by performing the learning process in two directions, from the past to the future and from the future to the past.

\subsection{GRU}

The GRU model has a gate mechanism to regulate the flow of information so as to remember context in multiple time steps (Cho et al., 2014). It uses an update gate and reset gate to determine what past information can be kept or forgotten. While GRU is similar to LSTM, it combines LSTM's forget and input gates into a single update gateway. The update gate decides how much past information is passed on while the reset gate decides how much is discarded. Figure 2 shows the structure of a GRU unit. GRU outperforms LSTM in terms of training time and prediction accuracy due to its very simple structure (Jianwei et al., 2019).

Figure 2. GRU Architecture

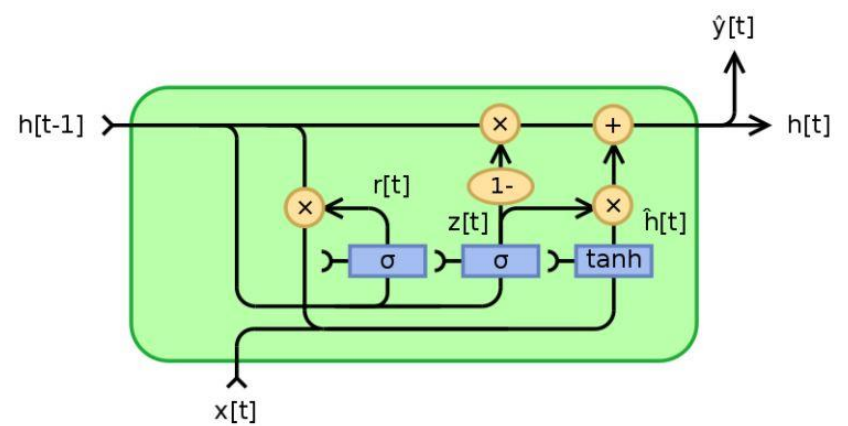

There are two gates in the GRU: the update and reset gates. These two gates, which decide what information is transmitted to the output, decide the information to be deleted and transferred. These operations are performed by the following equations:

$$
\begin{aligned}
& r_{t}=\sigma\left(W_{r} h_{t-1}+U_{r} x_{t}\right) \\
& \hat{\mathrm{h}}_{t}=\tanh \left(\mathrm{W}\left(r_{t} * h_{t-1}\right)+\mathrm{U} x_{t}\right)
\end{aligned}
$$




$$
\begin{aligned}
& z_{t}=\sigma\left(W_{z} h_{t-1}+U_{z} x_{t}\right) \\
& \left.h_{t}=\left(1-z_{t}\right) * h_{t-1}+z_{t} * \hat{\mathrm{h}}_{t}\right)
\end{aligned}
$$

$h_{t}$ and $h_{t-1}$ represent the output of the current and previous states, respectively while $r_{t}$ and $z_{t}$ indicate the reset and update gates, respectively. $\sigma$ is the logistic sigmoid function while $W_{r}$ and $U_{r}$ are the weight matrices.

\subsection{Accuracy Measures}

Mean absolute percent error (MAPE), root mean square error (RMSE) and mean absolute error (MAE) indicators defined by equations (11), (12) and (13), respectively were used to evaluate the performance of the models in this study.

In MAPE, the mean absolute error is calaculated to show how close the predicted and actual values are. Here, $\hat{y}_{i}$, is the predictive value, $y_{i}$ is the actual value and $\mathrm{n}$ is the length of the time series. However, because MAPE splits each error separately according to demand, its value is distorted.

$$
M A P E=\left(\sum_{t=1}^{n}\left|\frac{y_{i}-\hat{y}_{i}}{y_{i}}\right|\right) \frac{100}{n}
$$

MSE measures the difference between the observed and estimated values; RMSE is the square root of the MSE value. RMSE is a good measure of predictive accuracy, so it is often used as a standard metric to measure model performance. A low value of RMSE indicates high model performance.

$$
\mathrm{R} M S E=\sqrt{\frac{1}{n} \sum_{i=1}^{n}\left(y_{i}-\hat{y}_{i}\right)^{2}}
$$

MAE measures the difference between two continuous variables. The expected value of MAE for the best model is zero.

$$
M A E=\frac{1}{n} \sum_{i=1}^{n}\left|y_{i}-\hat{y}_{i}\right|
$$

\section{Data}

The data set used in the study consisted of 20 years (20012021) of the gold ounce price and five explanatory variables. The following economic indicators were used: crude oil price, consumer price index, effective exchange rate, effective federal funds rate and S\&P 500 stock market index. All these variables are assumed to affect the gold ounce price. Figure 3 shows the graph of the gold ounce price (Index Mundi, 2021) over the 20year period.
Figure 3. Gold Ounce Price (2001-2021)

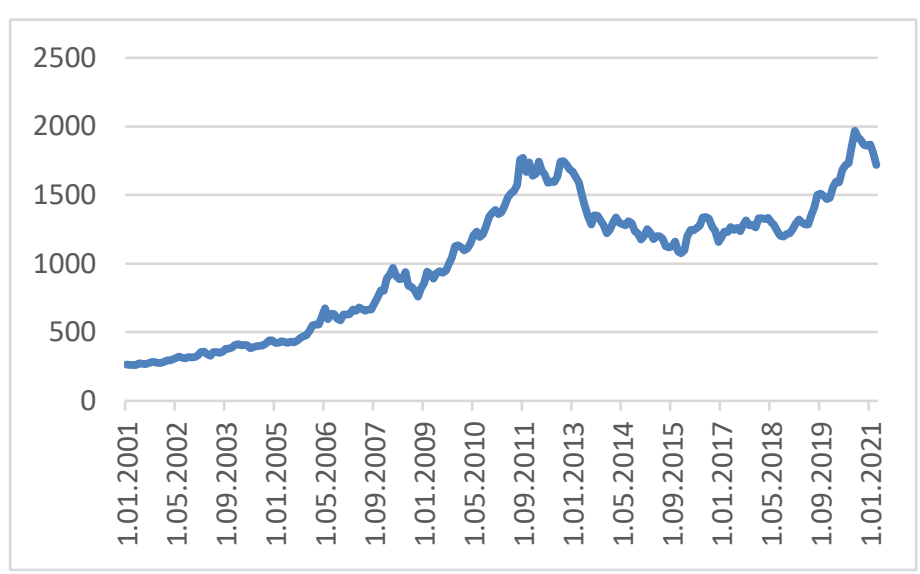

Table 1 shows the independent variables used in the established models and the sources they provide.

Table 1. Independent Variables

\begin{tabular}{|l|l|l|}
\hline Variable & Frequency & Source \\
\hline $\begin{array}{l}\text { Consumer Price } \\
\text { Index }\end{array}$ & Monthly & $\begin{array}{l}\text { Organization for } \\
\text { Economic Co-operation } \\
\text { and Development (2021) }\end{array}$ \\
\hline $\begin{array}{l}\text { Effective Federal } \\
\text { Funds Rate }\end{array}$ & Monthly & $\begin{array}{l}\text { Board of Governors of the } \\
\text { Federal Reserve System } \\
(2021)\end{array}$ \\
\hline $\begin{array}{l}\text { Real Broad } \\
\text { Effective } \\
\text { Exchange Rate }\end{array}$ & Monthly & $\begin{array}{l}\text { U.S. Energy Information } \\
\text { Administration (2021) }\end{array}$ \\
\hline S\&P 500 & Monthly for International \\
\hline Gold Price & Monthly & Yahoo Finance (2021) \\
\hline
\end{tabular}

Data were rescaled between 0 and 1 by normalization. After normalizing the dataset before training and testing, the first 170 observations (70\%), from January 2001 to January 2015, were allocated for training. Then, the last 72 observations (30\%), from February 2015 to February 2021, provided the test data to validate the accuracy of the proposed model.

Training of all models was carried out using Python 3.6 on Microsoft Windows 10 operating system. The LSTM model was implemented using the Keras library of deep learning. The selected hyperparameters for the validation experiments are listed in Table 2 .

Table 2. Hyperparameter Values

\begin{tabular}{|l|l|l|}
\hline & Hidden Layers & 3 \\
\cline { 1 - 3 } & No. of neurons & $128,64,32$ \\
\cline { 2 - 3 } LSTM/Bi-LSTM/GRU & Learning rate & 0.001 \\
\cline { 2 - 3 } & Optimizer & Adam \\
\cline { 2 - 3 } & Loss Function & MSE \\
\cline { 2 - 3 } & Time step & 1 \\
\hline
\end{tabular}


In the study, there are 3 hidden layers of the network that gives the prediction results. In the first layer, the input layer, six independent data are presented to the network as input. The first of the three hidden layers consists of 128 neurons, the second 64 neurons, and the third 32 neurons. The last layer is the output layer, which produces the prediction result based on the inputs.

\section{Results}

A $6 \times 244$ data set covering January 2001 to March 2021 was created with the five economic indicators and the gold ounce price. In this study, the price of gold, which is important for decision makers, was estimated using deep learning methods. One month ago values of the independent variables were used to estimate the future value of the dependent variable. The gold ounce price forecast was based on the input indicators. Across different experiments, the batch size and epochs directly affected the prediction accuracy. Some of the models that were tried while creating the model in the study are shown in Table 3. LSTM produced the best RMSE, MAPE and MAE values, followed in ascending order by Bi-LSTM and GRU.

The performances of the models listed in Table 3 were calculated by comparing the estimation results with the actual values. The model with the highest performance ratio is the 6th LSTM model.

Table 3. Performance results of models

\begin{tabular}{|l|l|l|l|l|l|}
\hline $\begin{array}{l}\text { Model } \\
\text { No }\end{array}$ & $\begin{array}{l}\text { Batch } \\
\text { Size }\end{array}$ & Epochs & MAPE & RMSE & MAE \\
\hline $\begin{array}{l}\text { Model 1 } \\
\text { (LSTM) }\end{array}$ & 32 & 500 & 6.13 & 100.931 & 87.02 \\
\hline $\begin{array}{l}\text { Model 2 } \\
\text { (LSTM) }\end{array}$ & 64 & 500 & 5.78 & 92.913 & 80.17 \\
\hline $\begin{array}{l}\text { Model 3 } \\
\text { (LSTM) }\end{array}$ & 128 & 500 & 6.53 & 102.844 & 89.28 \\
\hline $\begin{array}{l}\text { Model 4 } \\
\text { (LSTM) }\end{array}$ & 32 & 1000 & 8.18 & 136.839 & 117.92 \\
\hline $\begin{array}{l}\text { Model 5 } \\
\text { (LSTM) }\end{array}$ & 64 & 1000 & 5.55 & 94.795 & 79.74 \\
\hline $\begin{array}{l}\text { Model 6 } \\
\text { (LSTM) }\end{array}$ & 128 & 1000 & 3.48 & 61.728 & 48.85 \\
\hline $\begin{array}{l}\text { Model 1 } \\
\text { (Bi- } \\
\text { LSTM) }\end{array}$ & 32 & 500 & 7.57 & 126.614 & 109.05 \\
\hline $\begin{array}{l}\text { Model 2 } \\
\text { (Bi- } \\
\text { LSTM) }\end{array}$ & 64 & 500 & 4.99 & 84.614 & 71.06 \\
\hline $\begin{array}{l}\text { Model 3 } \\
\text { (Bi- } \\
\text { LSTM) }\end{array}$ & 128 & 500 & 4.33 & 72.977 & 60.59 \\
\hline $\begin{array}{l}\text { Model 4 } \\
\text { (Bi- } \\
\text { LSTM) }\end{array}$ & 32 & 1000 & 8.17 & 140.672 & 118.94 \\
\hline $\begin{array}{l}\text { Model 5 } \\
\text { (Bi- } \\
\text { LSTM) }\end{array}$ & 64 & 1000 & 6.36 & 111.520 & 92.70 \\
\hline $\begin{array}{l}\text { Model 6 } \\
\text { (Bi- } \\
\text { LSTM) }\end{array}$ & 128 & 1000 & 4.24 & 76.711 & 61.53 \\
\hline $\begin{array}{l}\text { Model 1 } \\
\text { (GRU) }\end{array}$ & 32 & 500 & 8.02 & 132.914 & 115.07 \\
\hline $\begin{array}{l}\text { Model 2 } \\
\text { (GRU) }\end{array}$ & 64 & 500 & 5.66 & 96.321 & 81.20 \\
\hline e-SSN 2148 & & & & & \\
\hline
\end{tabular}

e-ISSN: 2148-2683

\begin{tabular}{|l|l|l|l|l|l|}
\hline $\begin{array}{l}\text { Model 3 } \\
\text { (GRU) }\end{array}$ & 128 & 500 & 5.12 & 86.177 & 72.66 \\
\hline $\begin{array}{l}\text { Model 4 } \\
\text { (GRU) }\end{array}$ & 32 & 1000 & 8.52 & 144.977 & 123.56 \\
\hline $\begin{array}{l}\text { Model 5 } \\
\text { (GRU) }\end{array}$ & 64 & 1000 & 6.96 & 121.806 & 101.50 \\
\hline $\begin{array}{l}\text { Model 6 } \\
\text { (GRU) }\end{array}$ & 128 & 1000 & 4.91 & 87.425 & 71.24 \\
\hline
\end{tabular}

Following the LSTM model, the 6th Bi-LSTM and the 6th GRU models gave the best results. The epoch value of these three models is 1000 and the batch size value is 128 . It was observed that the model predicted better as these two values increased. Figures 4, 5 and 6 compare the actual ounce values of gold with the values predicted by each method.

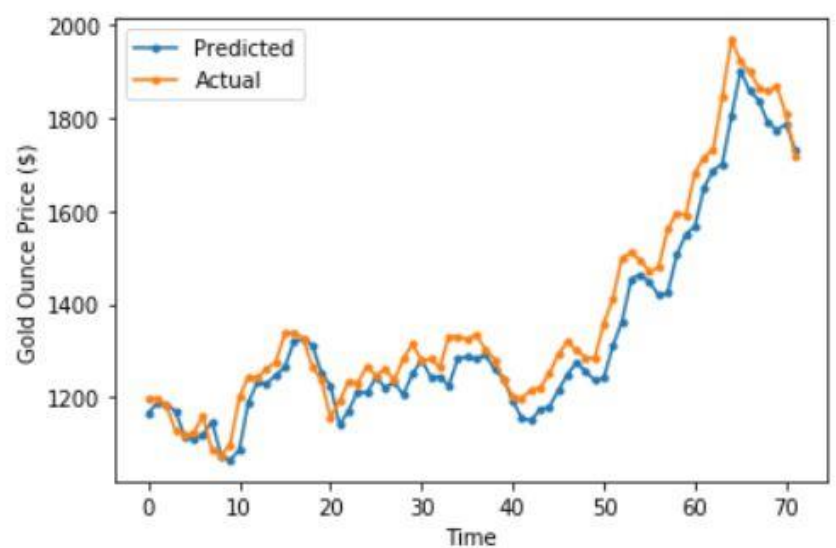

Figure 4. Actual and Predicted Gold Ounce Price with LSTM

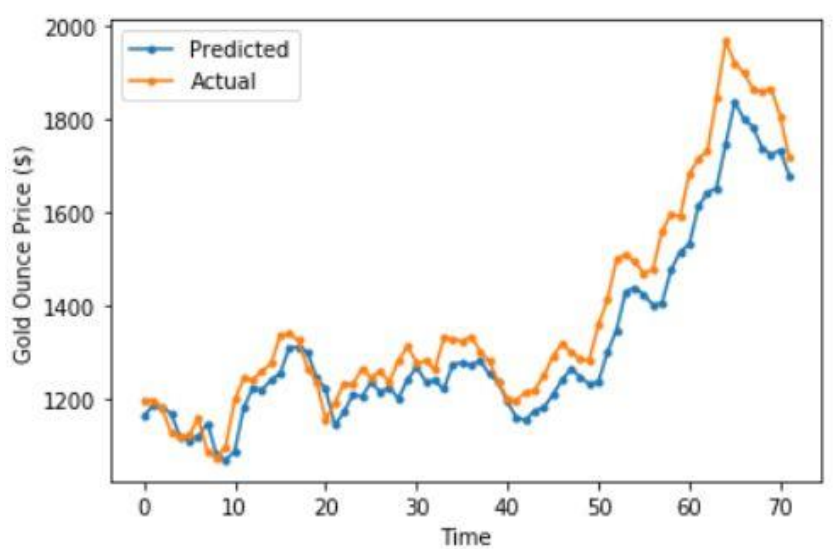

Figure 5. Actual and Predicted Gold Ounce Price with Bi-LSTM

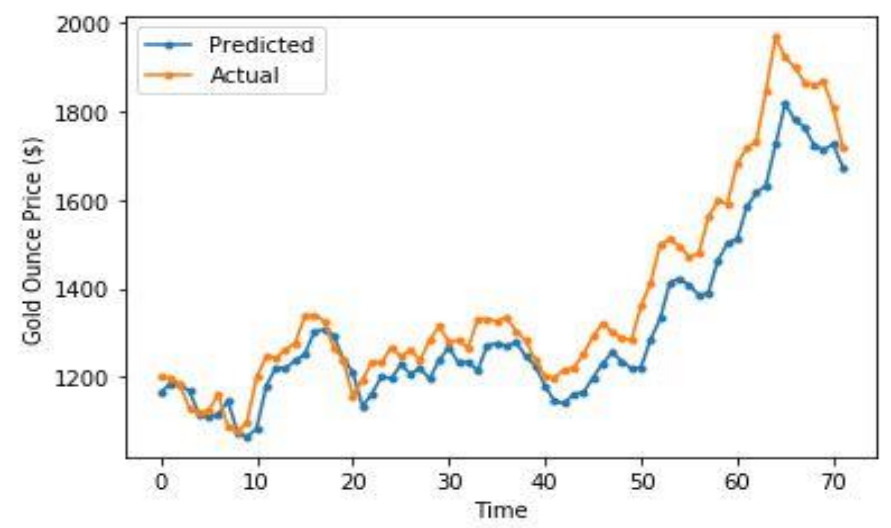

Figure 6. Actual and Predicted Gold Ounce Price with GRU 345 
Figure 7 shows the estimation results of all models are given together.

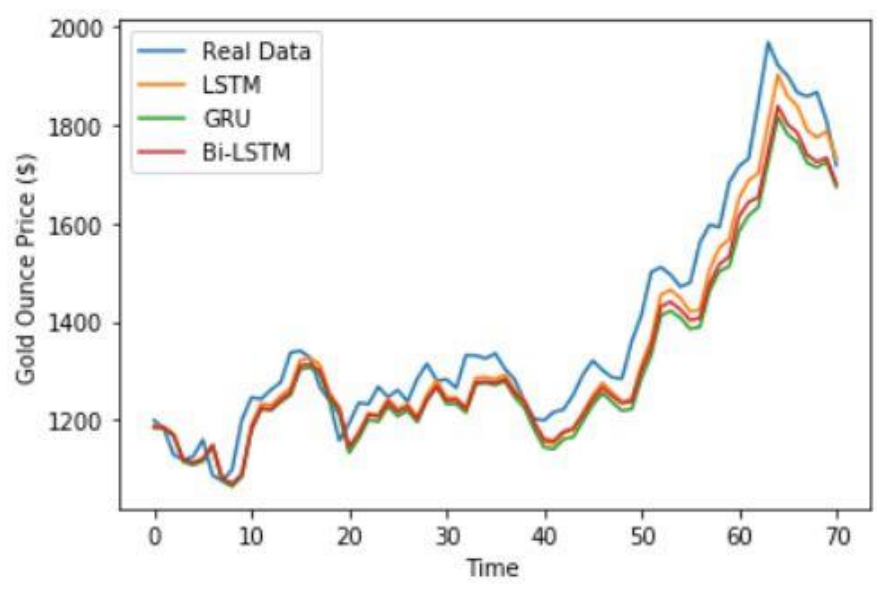

Figure 7. Actual and Predicted Gold Ounce Price with Models

\section{Discussion and Conclusion}

This compared the performance of three multivariate models (LSTM, Bi-LSTM and GRU) for predicting the gold price using monthly time series data. To evaluate their accuracy, MAE, RMSE and MAPE values were checked. Five economic indicators were used: crude oil price, consumer price index, stock market index, effective exchange rate and interest rate. Comparison of the actual gold price with each model's predicted values showed that LSTM performed best. The models also showed that economic indicators affect the gold ounce price, which is consistent with previous findings (Gokmenoglu \& Fazlollahi, 2015; Sivalingam et al., 2016; Chen \& Xu, 2019).

Deep learning applications have been widely used in various fields of science in recent years. In this context, the field of finance has also started to use deep learning applications effectively. The main reason for this is the highly volatile nature of financial markets and their capacity to be affected by many variables. For financial market stakeholders, this variability is both an opportunity and a major risk. Deep learning applications to be developed in this direction should provide investors with the opportunity to catch market opportunities on the one hand, and provide protection against risks that may arise in the market, on the other hand. This is important because the gold market is followed by governments and individual investors worldwide

The results suggest that LSTM, Bi-LSTM and GRU are all satisfactory estimators for the ordinal data used in this study. Future studies can use the models evaluated here to predict gold price while including other external variables. Prediction models can be made for gold price as well as other precious metals.

\section{References}

Alameer, Z., Abd Elaziz, M., Ewees, A. A., Ye, H., \& Jianhua, Z. (2019). Forecasting gold price fluctuations using improved multilayer perceptron neural network and whale optimization algorithm. Resources Policy, 61, 250-260.

Alpay, Ö. (2020). LSTM Mimarisi Kullanarak USD/TRY Fiyat Tahmini. Avrupa Bilim ve Teknoloji Dergisi, Ejosat Özel Sayı 2020 (ARACONF), 452-456.
Aygun, B., Kabakcı Gunay, E. (2021). Comparison of Statistical and Machine Learning Algorithms for Forecasting Daily Bitcoin Returns . Avrupa Bilim ve Teknoloji Dergisi , (21), 444-454.

Bank for International Settlements, Real Broad Effective Exchange Rate for United States [RBUSBIS], retrieved from FRED, Federal Reserve Bank of St. Louis; https://fred.stlouisfed.org/series/RBUSBIS, June 28, 2021.

Board of Governors of the Federal Reserve System (US), Effective Federal Funds Rate [FEDFUNDS], retrieved from FRED, Federal Reserve Bank of St. Louis; https://fred.stlouisfed.org/series/FEDFUNDS, June 28, 2021

Beckmann, J., \& Czudaj, R. (2013). Gold as an inflation hedge in a time-varying coefficient framework. The North American Journal of Economics and Finance, 24, 208-222.

Chen, R., \& Xu, J. (2019). Forecasting volatility and correlation between oil and gold prices using a novel multivariate GAS model. Energy Economics, 78, 379-391.

Cho, K., Van Merriënboer, B., Gulcehre, C., Bahdanau, D., Bougares, F., Schwenk, H., \& Bengio, Y. (2014). Learning phrase representations using RNN encoder-decoder for statistical machine translation. arXiv preprint arXiv: 1406.1078 .

Dar, A. B., \& Maitra, D. (2017). Is gold a weak or strong hedge and safe haven against stocks? Robust evidences from three major gold-consuming countries. Applied Economics, 49(53), 5491-5503.

Du, S., Li, T., Yang, Y., \& Horng, S. J. (2020). Multivariate time series forecasting via attention-based encoder-decoder framework. Neurocomputing.

Dutta, A., Kumar, S., \& Basu, M. (2020). A gated recurrent unit approach to bitcoin price prediction. Journal of Risk and Financial Management, 13(2), 23.

Erb, C. B., \& Harvey, C. R. (2013). The golden dilemma. Financial Analysts Journal, 69(4), 10-42.

Gangopadhyay, K., Jangir, A., \& Sensarma, R. (2016). Forecasting the price of gold: An error correction approach. IIMB management review, 28(1), 6-12.

Ghosh, D., Levin, E. J., Macmillan, P., \& Wright, R. E. (2004). Gold as an inflation hedge?.Studies in Economics and Finance.

Giannellis, N., \& Koukouritakis, M. (2019). Gold price and exchange rates: A panel smooth transition regression model for the G7 countries. The North American Journal of Economics and Finance, 49, 27-46.

Gokmenoglu, K. K., \& Fazlollahi, N. (2015). The interactions among gold, oil, and stock market: Evidence from S\&P500. Procedia Economics and Finance, 25, 478-488.

Gunduz, H. (2021). An efficient stock market prediction model using hybrid feature reduction method based on variational autoencoders and recursive feature elimination. Financial Innovation, 7(1), 1-24.

Güleryüz, D., Özden, E. (2020). The Prediction of Brent Crude Oil Trend Using LSTM and Facebook Prophet. Avrupa Bilim ve Teknoloji Dergisi , (20) , 1-9. DOI: 10.31590/ejosat.759302

Hassani, H., Silva, E. S., Gupta, R., \& Segnon, M. K. (2015). Forecasting the price of gold. Applied Economics, 47(39), 4141-4152.

Hochreiter, S., \& Urgen Schmidhuber, J. J. (1997). Long short term memory. Neural computation. MEMORY Neural Computation. 
Index Mundi, Gold Monthly Price- US Dollars per Troy Ounce, retrieved from https://www.indexmundi.com/commodities/?commodity $=$ go ld\&months $=120$, June 28, 2021

Jianwei, E., Ye, J., \& Jin, H. (2019). A novel hybrid model on the prediction of time series and its application for the gold price analysis and forecasting. Physica A: Statistical Mechanics and its Applications, 527, 121454.

Karim, F., Majumdar, S., Darabi, H., \& Harford, S. (2019). Multivariate LSTM-FCNs for time series classification. Neural Networks.

LeCun, Y., Bengio, Y., \& Hinton, G. (2015). Deep learning. nature, 521(7553), 436-444.

$\mathrm{Li}$, B. (2014). Research on WNN modeling for gold price forecasting based on improved artificial bee colony algorithm. Computational intelligence and neuroscience, 2014.

Liu, D., \& Li, Z. (2017). Gold price forecasting and related influence factors analysis based on random forest. In Proceedings of the Tenth International Conference on Management Science and Engineering Management (pp. 711-723). Springer, Singapore.

Livieris, I. E., Pintelas, E., \& Pintelas, P. (2020). A CNN-LSTM model for gold price time-series forecasting. Neural computing and applications, 32(23), 17351-17360.

Mensi, W., Beljid, M., Boubaker, A., \& Managi, S. (2013). Correlations and volatility spillovers across commodity and stock markets: Linking energies, food, and gold. Economic Modelling, 32, 15-22.

Munkhdalai, L., Munkhdalai, T., Park, K. H. O., Amarbayasgalan, T., Batbaatar, E., Park, H. W. O. O., \& Ryu, K. H. (2019). An end-to-end adaptive input selection with dynamic weights for forecasting multivariate time series. IEEE Access.

Nguyen, H. D., Tran, K. P., Thomassey, S., \& Hamad, M. (2021). Forecasting and Anomaly Detection approaches using LSTM and LSTM Autoencoder techniques with the applications in supply chain management. International Journal of Information Management

Olah, Christopher. (2015) Understanding LSTM Networks [Blog post]. Retrieved from http://colah.github.io/posts/2015-08UnderstandingLSTMs/

Organization for Economic Co-operation and Development. (2021, Feb. 4). Consumer Price Index: Total All Items for the United States [CPALTT01USM657N], Federal Reserve Bank of St. Louis, 2021. [Online]. Available: https://fred.stlouisfed.org/series/CPALTT01USM657N

Parisi, A., Parisi, F., \& Díaz, D. (2008). Forecasting gold price changes: Rolling and recursive neural network models. Journal of Multinational financial management, 18(5), 477-487

Parmezan, A. R. S., Souza, V. M. A., \& Batista, G. E. A. P. A. (2019). Evaluation of statistical and machine learning models for time series prediction: Identifying the state-of-the-art and the best conditions for the use of each model. Information Sciences.

Risse, M. (2019). Combining wavelet decomposition with machine learning to forecast gold returns. International Journal of Forecasting, 35(2), 601-615.

Schmidhuber, J. (2015). Deep learning in neural networks: An overview. Neural networks, 61, 85-117.

Schuster, M., \& Paliwal, K. K. (1997). Bidirectional recurrent neural networks. IEEE transactions on Signal Processing, 45(11), 2673-2681.
Shafiee, S., \& Topal, E. (2010). An overview of global gold market and gold price forecasting. Resources policy, 35(3), 178-189.

Shen, G., Tan, Q., Zhang, H., Zeng, P., \& Xu, J. (2018). Deep learning with gated recurrent unit networks for financial sequence predictions. Procedia computer science, 131, 895903.

Shen, Z., Zhang, Y., Lu, J., Xu, J., \& Xiao, G. (2020). A novel time series forecasting model with deep learning. Neurocomputing.

Sivalingam, K. C., Mahendran, S., \& Natarajan, S. (2016). Forecasting gold prices based on extreme learning machine. International Journal of Computers Communications \& Control, 11(3), 372-380.

U.S. Energy Information Administration. (2021, Feb. 4). Crude Oil Prices: West Texas Intermediate (WTI) - Cushing, Oklahoma [DCOILWTICO], Federal Reserve Bank of St. Louis, 2021. [Online].Available: https://fred.stlouisfed.org/series/DCOILWTICO

Xian, L., He, K., \& Lai, K. K. (2016). Gold price analysis based on ensemble empirical model decomposition and independent component analysis. Physica A: Statistical Mechanics and its Applications, 454, 11-23.

Wang, Y. S., \& Chueh, Y. L. (2013). Dynamic transmission effects between the interest rate, the US dollar, and gold and crude oil prices. Economic Modelling, 30, 792-798.

Weng, F., Chen, Y., Wang, Z., Hou, M., Luo, J., \& Tian, Z. (2020). Gold price forecasting research based on an improved online extreme learning machine algorithm. Journal of Ambient Intelligence and Humanized Computing, 1-11.

Yahoo Finance, S\&P500, Retrieved from https://finance.yahoo.com, June 28, 2021

Yazdani-Chamzini, A., Yakhchali, S. H., Volungevičienè, D., \& Zavadskas, E. K. (2012). Forecasting gold price changes by using adaptive network fuzzy inference system. Journal of Business Economics and Management, 13(5), 994-1010.

Yıldırım, D. C., Toroslu, I. H., \& Fiore, U. (2021). Forecasting directional movement of Forex data using LSTM with technical and macroeconomic indicators. Financial Innovation, 7(1), 1-36.

Zhang, P. (2003). Zhang, G.P.: Time Series Forecasting Using a Hybrid ARIMA and Neural Network Model. Neurocomputing 50, 159-175. Neurocomputing.

Zhang, P., \& Ci, B. (2020). Deep belief network for gold price forecasting. Resources Policy, 69, 101806. 